\title{
Do diagnóstico de transtorno de identidade de gênero às redescrições da experiência da transexualidade: uma reflexão sobre gênero, tecnologia e saúde
}

| 'Márcia Arán; ²Daniela Murta |

Resumo: Tendo como referência um estudo sobre as práticas de saúde dos principais serviços que prestam assistência a usuários(as) transexuais no Brasil, este artigo discute os desafios para a gestão de políticas públicas para essa população, particularmente, a necessidade do diagnóstico de Transtorno de Identidade de Gênero como condição de acesso. Para iluminar o debate, realiza-se uma reflexão sobre gênero, tecnologia e saúde a partir das contribuições de Bernice Hausman e Joanne Meyerowitz sobre a constituição do fenômeno da transexualidade na metade do século passado. Destaca-se a importância da análise dos avanços da tecnologia médica e da influência da revolução dos costumes na problematização da imutabilidade do sexo e na construção da categoria de gênero como condição para compreender o motivo pelo qual a regulamentação do acesso à saúde para a modificação das características corporais do sexo ficou associada à definição da condição transexual. Por último, discute-se que se inicialmente a institucionalização da assistência a transexuais no Brasil esteve associada ao modelo estritamente biomédico, a noção de saúde integral deve promover uma abertura para as redescrições da experiência transexual numa articulação permanente entre os saberes biopolíticos dominantes e uma multiplicidade de saberes locais e minoritários.

> Palavras-chave: transexualidade, saúde, gênero, tecnologia, subjetividade, cultura.

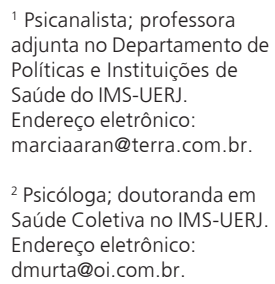

${ }^{1}$ Psicanalista; professora adjunta no Departamento de Políticas e Instituições de Saúde do IMS-UERJ.

Endereço eletrônico: marciaaran@terra.com.br.

2 Psicóloga; doutoranda em Saúde Coletiva no IMS-UERJ. Endereço eletrônico: dmurta@oi.com.br. 
Tendo como referência um estudo sobre as práticas de saúde dos principais serviços que prestam assistência a usuários(as) transexuais no Brasil, este trabalho pretende discutir os desafios para a gestão de políticas públicas para essa população, particularmente, a necessidade do diagnóstico de Transtorno de Identidade de Gênero como condição de acesso. Para iluminar este debate, realizaremos uma reflexão sobre gênero, tecnologia e saúde a partir das contribuições de Bernice Hausman (1995) e Joanne Meyerowitz (2002) sobre a constituição do fenômeno da transexualidade na metade do século passado. Pretendemos destacar a importância da tecnologia médica no advento da "mudança de sexo", assim como a influência da revolução dos costumes que propiciaram a problematização da imutabilidade do sexo e a construção da categoria de gênero. Nossa hipótese de trabalho é que somente a partir da compreensão desses fenômenos poderemos entender o motivo pelo qual a regulamentação do acesso à saúde para a modificação das características corporais do sexo ficou associada à definição da condição transexual - hoje descrita como transtorno de identidade de gênero - e os deslocamentos possíveis deste modelo normativo de patologização da transexualidade. Neste sentido, se de início a institucionalização da assistência a transexuais no Brasil esteve associada ao modelo estritamente biomédico, hoje a noção de saúde integral há que promover uma abertura para as redescrições da experiência transexual numa articulação permanente entre os saberes biopolíticos dominantes e uma multiplicidade de saberes locais e minoritários.

\section{Transexualidade e saúde no Brasil}

Os serviços que prestam assistência a transexuais que procuram tratamento para a realização do processo transexualizador no Brasil foram organizados a partir da regulamentação desta prática, após a publicação da Resolução no 1.482/97 do Conselho Federal de Medicina. Considerado um atendimento de alta complexidade, a maioria destes serviços encontra-se em hospitais públicos universitários, localizados nas regiōes Sul e Sudeste do país. Em pesquisa em andamento intitulada "Transexualidade e Saúde: condições de acesso e cuidado integral” (IMSUERJ/MCT/CNPq/MS/SCTIE/DECIT) -, realizamos um levantamento ${ }^{1}$ preliminar desses serviços ${ }^{2}$ e constatamos que praticamente todos possuem um ambulatório especializado para o atendimento dessa clientela, composto por uma equipe interdisciplinar constituída por profissionais do quadro permanente do 
hospital. De modo geral, a equipe é composta por cirurgião reconstrutor genital (urologista e/ou ginecologista), psiquiatra, psicólogo, endocrinologista, cirurgião plástico, assistente social e enfermagem, sendo que o número de profissionais envolvidos varia de acordo com cada instituição. Os profissionais de outras especialidades que participam desses serviços, como geneticista, cirurgião geral, anestesista, mastologista, otorrinolaringologista e fonoaudiólogo, normalmente atendem sob demanda. Além disso, alguns desses serviços têm convênio com uma assessoria jurídica para mudança do nome civil, que está condicionada, na maioria dos casos, à realização da cirurgia de transgenitalização. Nota-se que um dos principais desafios para implementação desta modalidade de assistência é a capacitação profissional da equipe interdisciplinar e medidas de humanização, para que se possa garantir um atendimento de qualidade e livre de discriminação.

Em todos os serviços analisados, as intervenções médico-cirúrgicas atendem aos critérios estipulados pela Resolução no 1.652/2002 do CFM, que determinam o prazo mínimo de dois anos de acompanhamento terapêutico como condição para realização da cirurgia de transgenitalização, bem como a maioridade e o diagnóstico de transexualismo. Transcorridos os dois anos, caso o(a) usuário(a) seja considerado(a) transexual e tenha condiçóes clínicas, pode ser encaminhado(a) para a realização do procedimento cirúrgico. No entanto, devido à dificuldade de agendamento das cirurgias, os(as) usuários(as) transexuais têm permanecido por muito mais tempo aguardando a realização da cirurgia. Em caso de internação médico-hospitalar, na maioria das vezes os homens e mulheres transexuais são internados na enfermaria em conformidade ao sexo com o qual se identificam socialmente, a despeito do nome que conste no registro civil, ou num leito específico para esse programa assistencial.

Desde 1997 vem ocorrendo um crescimento significativo do número de usuários(as) que se definem como transexuais e que procuram tratamento para a realização do processo transexualizador. Tendo como referência os dados coletados na pesquisa referida, no início de 2008, 700 mulheres transexuais ( $\mathrm{MtF}$ - male to female) e 120 homens transexuais (FtM - female to male) já haviam sido atendidos. Deste montante, 366 usuários(as) encontram-se em atendimento no momento 256 mulheres transexuais $(\mathrm{MtF})$ e 22 homens transexuais ( $\mathrm{FtM})$ estão em acompanhamento pré-operatório e 57 mulheres transexuais $(\mathrm{MtF})$ e 31 homens transexuais (FtM) estão em acompanhamento pós-operatório. $\mathrm{O}$ número de 
cirurgias já realizadas em mulheres transexuais $(\mathrm{MtF})$, aproximadamente 160 até o início de 2008, é bem superior ao de cirurgias realizadas em homens transexuais (FtM), aproximadamente 30 no mesmo período, Nestes casos, a maioria são modificações de caracteres sexuais secundários, já que a transexualização de mulher para homem é mais complexa e permanece sendo uma cirurgia experimental. No entanto, é importante destacar que os números são aproximados. Considerando o aumento da visibilidade desta modalidade de assistência no último ano, é provável que o número de pacientes atendidos seja bem mais expressivo. Além disso, esses números não refletem a provável demanda reprimida e as barreiras de acesso na busca por esse tratamento, principalmente pelo fato de não existir uma política de atenção básica para essa clientela. Não temos também o registro dos atendimentos realizados no setor privado.

O processo de cuidado relatado pelos profissionais consiste no atendimento clínico, particularmente na hormonioterapia, no atendimento psicológico e psiquiátrico, na assistência social e na realização das cirurgias de transgenitalização e de caracteres sexuais secundários. Esses procedimentos foram normatizados por meio da Portaria GM no. 1.707, de 18 de agosto de 2008 (BRASIL, 2008a) do Ministério da Saúde, que estabeleceu diretrizes técnicas e éticas para o processo transexualizador no SUS. De acordo com essa portaria, o Ministério da Saúde reconhece que a orientação sexual e a identidade de gênero são determinantes e condicionantes da situação de saúde, e que o mal-estar e o sentimento de inadaptação em relação ao sexo anatômico dos usuários transexuais devem ser acolhidos e tratados pelo SUS, seguindo os preceitos da universalidade, integralidade e da equidade da atenção.

$\mathrm{Na}$ realidade brasileira, usuários(as) transexuais que chegam aos serviços de saúde encontram-se, muitas vezes, numa condição de extrema vulnerabilidade psíquica, física e social, sendo a "saúde" não apenas o que vai proporcionar o tratamento necessário e desejado, mas, muito provavelmente, o que permitirá a construção de uma rede de reconhecimento e inclusão social para estas pessoas. Isto porque, apesar da fundamental importância da constituição dos movimentos sociais - principalmente do movimento LGBTT e do coletivo nacional de transexuais -, muitas pessoas trans chegam aos serviços sem informações básicas sobre seus direitos e condição. Além disso, a maioria dos usuários(as) se identifica como homem ou como mulher e não pretende revelar ou sequer compartilhar a 
vivência da transexualidade com alguém; muitos(as) perderam seu vínculo familiar ou mudaram de cidade; e outros(as) têm dificuldades concretas provenientes de problemas com a documentação ou mesmo com a profissionalização. Neste sentido, faz parte da rotina da maioria dos serviços acolher uma demanda social - a qual pode envolver diretamente um trabalho de assistência social - que se expressa através de intenso sofrimento psíquico.

Resumidamente, as principais técnicas de cuidado são as seguintes:

\section{Tratamento hormonal}

O tratamento endocrinológico tem como objetivo induzir o aparecimento de caracteres sexuais secundários compatíveis com a identificação de gênero através de terapia hormonal, assim como possibilitar o acompanhamento clínico. Este tratamento deve ser realizado pelo resto da vida e só será interrompido para realização da cirurgia. É de fundamental importância estabelecer a dose ideal do medicamento para cada pessoa, destacando-se o fato de que não há necessidade de doses elevadas de hormônios para se alcançar os efeitos desejados ou alcançá-los mais rapidamente. A terapia hormonal prescrita após o diagnóstico de transexualismo pode ser realizada pelo endocrinologista ou urologista. A maioria dos(as) usuários(as) chega aos serviços já tendo feito uso anterior (automedicação) de algum tipo de hormônio por indicação de amigos ou através de informações coletadas na internet. No caso de mulheres transexuais $(\mathrm{MtF})$, na automedicação normalmente são utilizadas pílulas anticoncepcionais em grande quantidade - as pacientes tomam muitos comprimidos por dia, acreditando que assim terão um efeito mais rápido - e hormônios indicados para reposição hormonal de mulheres na menopausa. Além disso, a literatura especializada aponta para a necessidade de pesquisas empíricas sobre os efeitos colaterais do uso prolongado de hormônios.

No processo transexualizador, a terapia hormonal para mulheres transexuais $(\mathrm{MtF})$ consiste na administração de antiandrogênicos (hormônios com a finalidade de diminuir as características masculinas) e estrogênio, através de doses adequadas individualmente para um melhor resultado terapêutico e com menos efeitos colaterais. Dos estrogênios os mais prescritos são 17ß-Estradiol e dos antiandrogênicos, o Acetato de Ciproterona (nome comercial - Androcur®), porém existem várias outras formas de administração do medicamento. No caso dos homens transexuais (FtM), existem diversas opções de terapia de reposição androgênica 
disponíveis no mercado. A testosterona é o principal hormônio utilizado para induzir o desenvolvimento dos caracteres sexuais secundários masculinos, podendo ser administrada por injeções intramusculares de ésteres de testosterona, vias transdérmicas como adesivos, géis de testosterona e de di-hidrotestosterona (DHT) e sistemas subcutâneos, como o adesivo bucal e o undecanoato de testosterona oral. ${ }^{3}$

\section{Cirurgias de redesignação sexual}

$\mathrm{Na}$ cirurgia de redesignação sexual de mulheres transexuais $(\mathrm{MtF})$, utiliza-se como tática cirúrgica da transgenitalização a retirada ou desmembramento do pênis, a retirada parcial do escroto, orquiectomia bilateral, uretroplastia, construção da neovagina, neoclitoroplastia e neovulvoplastia. No que se refere à tática para modificação dos caracteres sexuais secundários, utiliza-se mamoplastia, cricotireoplastia, cirurgia de cordas vocais, cirurgia feminilizante de face e contorno corporal e realização de depilação definitiva. Para cada etapa da tática cirúrgica, tanto da transgenitalização quanto da modificação de caracteres secundários, há diversas técnicas descritas. Além disso, é importante realçar que as cirurgias de modificação de caracteres sexuais secundários não são aplicáveis a todas as usuárias, dependendo do resultado individual da hormonioterapia feminilizante. Já na redesignação sexual de homens transexuais (FtM) - a qual permanece como cirurgia experimental ${ }^{4}$-, são utilizadas como táticas cirúrgicas de transgenitalização a histerossalpingo-ooforectomia, a colpectomia, a neofaloplastia e a escrotoplastia. Do mesmo modo que na transgenitalização de mulheres transexuais $(\mathrm{MtF})$, nesses procedimentos leva-se em conta a diversidade de técnicas descritas para cada etapa da tática cirúrgica. Nesses casos, ainda que tenha papel fundamental no processo transexualizador, podendo ser realizada antes (ou independentemente) da cirurgia genital, a mastectomia bilateral é definida como cirurgia de caractere sexual secundário. ${ }^{5}$

Como se pode perceber, trata-se de cirurgias de grande porte e que têm caráter irreversível. Neste sentido, algumas considerações se fazem necessárias. Primeiro, é de fundamental importância que os(as) usuários(as) sejam esclarecidos de todas as conseqüências funcionais e estéticas desses procedimentos, além dos possíveis riscos. O contato prévio com os médicos e com outros pacientes que já realizaram as cirurgias poderá ser de grande valia para ajudar na tomada de decisão em relação à efetivação da cirurgia. Além disso, é importante considerar em que contexto se 
dá a opção pela transformação corporal, já que em função da extrema vulnerabilidade da população trans no país, a cirurgia de transgenitalização pode se apresentar como uma tábua de salvação, constituindo-se como única possibilidade de inclusão social. Assim, constatamos que alguns homens e mulheres transexuais podem desejar a cirurgia de transgenitalização pela exclusiva necessidade de reconhecimento social mais amplo, o que nos faz pensar que a cirurgia não necessariamente seria indicada se vivêssemos num mundo onde a diversidade de gênero fosse possível. Estas pessoas não apenas já têm uma vida afetiva e sexual satisfatória, como também já são reconhecidas pelo gênero a que dizem pertencer e em outras condiçóes poderiam permanecer como estão, desde que pudessem realizar a mudança do nome civil. Nestes casos, a real necessidade de cirurgia poderá ser relativizada. Porém, outras pessoas consideram a realização de modificações corporais, inclusive a cirurgia de transgenitalização, um evento vital para a construção de si, sendo a possibilidade de modificação corporal fundamental para o delineamento de seus projetos de vida. Entre estes extremos há um continuum de possibilidades que devem ser consideradas. Como por exemplo, muitos homens trans que desejam a realização de cirurgias para a modificação de caracteres sexuais secundários (como a mastectomia), mas não desejam realizar a de cirurgia de transgenitalização. É por isso que a individualização do cuidado é parte constitutiva de qualquer projeto baseado na integralidade da assistência.

\section{Tratamento psicológico e psiquiátrico}

A maioria dos serviços tem como orientação terapêutica a realização do diagnóstico psiquiátrico de transtorno de identidade de gênero, sendo que a principal preocupação é a regulamentação do acesso e a necessidade de se ter certeza sobre a decisão da realização de modificações corporais, em especial no que se refere à cirurgia de transgenitalização, dado seu caráter irreversível. O diagnóstico psiquiátrico é realizado no início do tratamento, através da avaliação clínica psiquiátrica e, em alguns casos, são utilizados testes psicológicos. A partir de avaliação especializada, os usuários e usuárias são encaminhados para atendimento psicológico em grupo ou individual, como também para acompanhamento psiquiátrico quando necessário. ${ }^{6}$

É fato que a vivência da transexualidade pode acarretar problemas relacionados à vida psíquica, em geral marcada pelo trauma do não-reconhecimento, da injúria 
e da exclusão social, assim como por dificuldades provenientes de problemas familiares e de relacionamentos sexuais e afetivos. Esta experiência pode se constituir num intenso sofrimento psíquico, que aparece muitas vezes sob a forma de tentativas de suicídio, depressão, transtornos alimentares e angústias das mais diversas formas, provocadas não apenas pelo conflito de não-pertencimento ao sexo biológico, como também pelas inúmeras consequências sociais, éticas, jurídicas e culturais intrínsecas a esta condição. Todavia, ainda que a psiquiatria costume descrever essas experiências em termos de comorbidade, não podemos perder de vista os contextos cultural e social nos quais esses sintomas aparecem, já que na transexualidade o risco de patologização de um problema social está sempre presente. Isto não significa, no entanto, que todas as pessoas trans padeçam do mesmo sofrimento e que tenham a mesma trajetória de vida. É surpreendente constatar como, em condiçôes adversas, homens e mulheres transexuais tenham conseguido construir suas vidas de forma satisfatória e produtiva. A partir da análise de entrevistas em profundidade com usários(as) dos serviços de saúde, temos afirmado que existem várias formas de subjetivação e construções de gênero na transexualidade (ARÁN; ZAIDHAFT; MURTA, 2008; ARÁN; MURTA; LIONÇO, 2008; MURTA, 2007; ARÁN, 2006; LIONÇO, 2006; BENTO, 2006; ZAMBRANO, 2003). Mais do que isto, consideramos que a transexualidade é uma categoria em constante negociação. Neste sentido, se ela pode expressar em parte a experiência de sujeitos que solicitam modificações corporais do sexo em função de um sentimento de desacordo entre sexo e gênero, no nosso ponto de vida ela não expressa um modo de funcionamento psíquico específico, nem mesmo uma estrutura clínica ${ }^{7}$.

A partir deste breve panorama do estado da arte da assistência a transexuais no Brasil, podemos perceber o enorme avanço que tem significado a gestão de políticas públicas para esta população. Vários atores sociais contribuíram para a promoção do debate público sobre o tema, dando visibilidade à vulnerabilidade da população trans no país. Dentre elas, destaca-se a valiosa contribuição dos coordenadores dos programas assistenciais que construíram um espaço de atenção a essa clientela, muitas vezes enfrentando enorme resistência institucional devido não apenas ao preconceito, à homofobia e à discriminação incutidos em algumas práticas de saúde, como também a dificuldades de compreensão da importância do princípio da equidade. ${ }^{8}$ Além disso, foi de fundamental importância a ação do Ministério 
Público Federal para a inclusão da cirurgia de transgenitalização na tabela de procedimentos do SUS em 2001. A instituição do Comitê Técnico Saúde da População LGBT (Lésbicas, Gays, Bissexuais, Travestis e Transexuais) pela Portaria GM no. 2.227 em 2004, a criação do Coletivo Nacional de Transexuais em 2005, as reuniōes e seminários realizados no Ministério da Saúde sobre o processo transexualizador no SUS e as contribuição de pesquisadores acadêmicos permitiram o estabelecimento de pactuações sobre propostas de saúde integral. ${ }^{9}$ Todas essas iniciativas culminaram na publicação da Portaria no 1.707/2008 do Ministério da Saúde, referida acima, que institui no Sistema Único de Saúde (SUS) o Processo Transexualizador, através da constituição de serviços de referência que estejam habilitados a prestar atenção integral e humanizada a transexuais. ${ }^{10}$ Todavia, as discussões sobre o tema não se encerram. É de fundamental importância o fortalecimento das medidas anunciadas pelo Ministério da Saúde com o estabelecimento de prazos e metas para o credenciamento dos serviços; a promoção de uma política de atenção básica; a imediata discussão sobre a especificidade da assistência a homens transexuais (FtM); a construção de uma rede com sistema jurídico para a mudança do nome civil, ${ }^{11}$ entre outras.

No entanto, do nosso ponto de vista, o grande desafio na regulação desta prática consiste em transitar entre a importância da normatização do acesso à saúde e o reconhecimento do sofrimento psíquico - implícitos no diagnóstico de transtorno de identidade de gênero - e a necessidade da problematização da restrição da compreensão da experiência da transexualidade a partir deste diagnóstico psiquiátrico - implícitos na noção de saúde integral. ${ }^{12}$

Ainda que a transexualidade esteja definida como um transtorno mental e a institucionalização da assistência a essa população esteja baseada em um modelo biomédico, o fato de se definir uma política de saúde integral tendo como referência os princípios do SUS permite uma ampliação da noção de saúde, a qual não deve ficar restrita à ausência de doença. Desta forma, por um lado, deve-se considerar a noção de sofrimento psíquico e corporal como critério de acesso à saúde sem que necessariamente este sofrimento tenha que ser patologizado, já que um conceito positivo de saúde pressupõe que esta não se define nem por uma média nem por um ideal, mas por sua plasticidade normativa (MARTINS, 2004). Além disso, na perspectiva da integralidade, é fundamental levarmos em consideração a especificidade de cada encontro para a elaboração do projeto terapêutico de cada 
paciente de acordo com seus sofrimentos, suas expectativas, seus temores e seus desejos (MATTOS, 2004). Assim, o projeto terapêutico de modificação corporal de sexo deve levar em conta a diversidade e a singularidade das narrativas trans, nem todas as pessoas desejam e necessitam os mesmos procedimentos de cuidado. Por outro lado, como dissemos anteriormente, mesmo considerando o inegável benefício que alguns serviços têm prestado a usuários transexuais, a exigência do diagnóstico psiquiátrico como condição de acesso ao tratamento permanece como um problema, sendo necessário colocar em questão a noção de "transexual verdadeiro", fortemente veiculada nos manuais diagnósticos, que acaba por conceber um comportamento fixo, rígido, adequado às normas de feminilidade ou de masculinidade. ${ }^{13}$

Para iluminar a complexidade deste debate, na segunda parte deste artigo discutiremos a genealogia do diagnóstico de transtorno de identidade de gênero, com o objetivo de compreender como a regulamentação do acesso ao processo transexualizador ficou atrelada à necessidade de definição da condição transexual. Pretende-se destacar como, na metade do século XX, um conjunto de acontecimentos - que vai desde o avanço da tecnologia médica até uma maior liberação sexual que permitiu a discussão sobre a imutabilidade do sexo - constituiu o fenômeno da transexualidade num contexto de redefinição dos conceitos de sexo e gênero no meio cientifico. ${ }^{14}$ Neste sentido, qualquer reflexão sobre o tema deve partir da constatação de que o diagnóstico de Transtorno de Identidade de Gênero foi uma forma de regulamentar a demanda de transexuais por mudança de sexo e que a própria definição de transexualidade somente se tornou possível nesse contexto. $\mathrm{O}$ que não significa que agora, na aurora do século XXI, tais pressupostos não possam ser problematizados, levando-se em consideração novas redescrições da experiência transexual.

\section{Genealogia do transtorno de identidade de gênero}

Ao pesquisar sobre a genealogia do diagnóstico de transtorno de identidade de gênero, não restam dúvidas de que a cirurgia realizada em Georges Jorgensen, que se tornou Christine em 1952, foi um marco para a definição da experiência da transexualidade tal como a compreendermos hoje. A midiatização da história de Jorgensen, operado por Christian Hamburger na Dinamarca e posteriormente atendido por Harry Benjamin nos Estados Unidos, vai contribuir enormemente para a reflexão sociológica sobre a identidade sexual e a construção da categoria de gênero. Da mesma forma, o aumento significativo das demandas por tratamento 
que ocorre a partir da divulgação deste fato surpreenderá o meio científico e irá suscitar um enorme investimento em pesquisas e estudos para compreensão do que Harry Benjamin chamará de "fenômeno transexual". Segundo Pierre-Henri Castel (2001), este caso ilumina um conjunto de acontecimentos que revolucionou a forma de compreender a relação entre sexo e gênero no âmbito científico. A tradição americana da sociologia empírica e sua teoria da influência do ambiente na construção da sexualidade criam um campo de investigação sobre a socialização de indivíduos intersexuais, de meninos com órgãos genitais acidentalmente mutilados e de transexuais. Neste contexto, psicólogos e sociólogos questionam quais seriam os principais determinantes da identidade sexual dos indivíduos. Muitos casos serão descritos, divulgados e problematizados, configurando novos dispositivos de saber e poder não apenas sobre a sexualidade (FOUCAULT, 1988) mas, principalmente, sobre as técnicas de normatização, correção e educação sexual.

Com efeito, a partir da Segunda Guerra Mundial, assistimos ao surgimento de um novo modelo de produção de subjetividades fortemente relacionado às novas tecnologias. Um regime que se configura, sobretudo, pelo impacto das novas tecnologias na construção de si, as quais têm como referência não mais a soberania e a disciplina, mas o que Deleuze (1992) propõe chamar de sociedade de controle e Donna Haraway (1991), de tecnopoder. Assim, se na sociedade disciplinar a arquitetura e a ortopedia serviam de modelo para entender a relação entre corpo e poder, nas sociedades de controle assistimos progressivamente a miniaturização, internalização e introversão dos dispositivos de vigilância. A principal característica destas novas tecnologias é tomar a forma do corpo que controlam (HARAWAY, 1991; PRECIADO, 2008; ARÁN; CORRÊA, 2009).

É nesse contexto de revolução tecnológica da biomedicina e de uma maior liberdade sexual que se dá o reconhecimento da possibilidade de mudança de sexo. O termo "transexualismo" foi utilizado pela primeira vez em 1910 por Magnus Hirschfeld para se referir ao que o autor denominou de "transexualismo psíquico" (CASTEL, 2001), sendo retomado 40 anos depois, quando o Dr. David O. Cauldwell trouxe a público um estudo de caso sobre um transexual feminino no artigo intitulado "Psychopatia Transexuallis"(1949). A partir de então, começaram a ser esboçadas as especificidades da transexualidade e delineadas novas teorizações médicas e sociológicas - como os estudos de Harry Benjamin (1966), John Money (1969) e Robert Stoller $(1973,1982)$-, que, somadas ao progresso da biologia e 
da viabilidade técnica para adequação do corpo à identidade de gênero, deslocaram essa experiência de uma situação individual e absolutamente marginal para um problema médico-legal reconhecido e passível de tratamento.

Frente a isso, tornou-se necessário que as redesignações sexuais fossem inseridas em processos terapêuticos formais e que os procedimentos fossem normatizados, com a criação de centros de transgenitalização e a elaboração de protocolos de atendimento com base nas definições de Harry Benjamin. Com este objetivo, Norman Fisk, em 1973, fundamenta uma nosografia psiquiátrica para o transexualismo, ancorada fundamentalmente num autodiagnóstico. Em 1977 essa condição é incorporada à categoria psiquiátrica de "Disforia de Gênero", que incluía outras "enfermidades" ligadas à identidade de gênero. Esta denominação, que designa a insatisfação decorrente da discordância entre o sexo biológico e a identidade sexual de um indivíduo, aponta como única possibilidade de tratamento a realização da cirurgia de conversão sexual e a utilização de hormônios (MURTA, 2007). Posteriormente, em 1980, a condição transexual foi agregada ao manual diagnóstico psiquiátrico DSM III (Manual Diagnóstico e Estatístico das Desordens Mentais) e em 1994, com a publicação do DSM IV, o termo "transexualismo" foi substituído por "Transtorno de Identidade de Gênero" (TIG). ${ }^{15}$

Assim, embora as descrições do século XIX sobre a transexualidade tenham sido muito importantes para a construção genealógica do Transtorno de Identidade de Gênero, o efetivo reconhecimento da experiência transexual como condição médica se fez em um contexto específico de progresso científico e expressivas transformações sociais. Nesse sentido, alguns autores, como Bernice Hausman, argumentam que só é possível compreender o fenômeno da transexualidade a partir do desenvolvimento da tecnologia médica e do pacto realizado entre médicos e transexuais para possibilitar a mudança de sexo. Outros, como Joanne Meyerowitz, argumentam que a noção de transexualidade é uma consequência da revolução dos costumes propiciada pela problematização do caráter imutável do sexo e posteriormente pelo surgimento da categoria de gênero.

\section{A tecnologia médica e o advento da possibilidade de "mudança de sexo"}

O argumento central de Bernice Hausman (1995) é que a emergência da transexualidade na metade do século XX estaria diretamente associada ao 
desenvolvimento da tecnologia, particularmente da endocrinologia e da cirurgia plástica. Para a autora, embora pareça evidente, a relação entre tecnologia médica, prática médica e o advento da possibilidade de "mudança de sexo" não estaria sendo suficientemente destacada nos estudos de gênero, os quais, na sua concepção, entendem a transexualidade como uma inadequação entre sexo e gênero. De acordo com seu argumento, o que define a experiência transexual é menos a percepção desta incoerência e mais a necessária e fundamental relação conceitual e material desses sujeitos com o discurso e a prática médica. A partir desta concepção, transexuais só adquirem reconhecimento no momento em que procuram o tratamento, sendo que sua posição subjetiva dependeria de uma relação necessária com a definição médica e seu discurso.

Assim, embora Hausman (1995) considere que transexuais sejam alvo de discriminação e violência tanto quanto travestis e em certa medida homossexuais, o que poderia definir uma situação política semelhante, estas experiências não seriam análogas nem como minoria sexual e nem mesmo como objeto de estudo. Diferentemente da homossexualidade e da travestilidade, para a autora a transexualidade só pode ser compreendida através da relação com a tecnologia médica. Neste sentido, seria importante destacar que justo no momento em que homossexuais conseguem sair do Código Internacional das Doenças em 1973, através de uma luta pela despatologização da homossexualidade, transexuais entram no DSM afirmando que seu problema não era um "desvio sexual", mas uma condição retificável pela tecnologia médica disponível.

É apenas pela análise da aliança entre transexuais e sua clínica - e, em um nível mais extenso, a relação dialética entre a tecnologia de "mudança de sexo" e a demanda pela mudança de sexo - que podemos entender como o transexualismo foi aceito pelo menos em algumas tendências atuais do discurso médico, uma condição essencial para sua emergência como uma forma pública de identidade. (HAUSMAN, 1995, p. 4).

Desta forma, a necessidade da racionalidade médica de diferenciar transexuais de outras "condições sexuais", o que produz e influencia o "comportamento transexual verdadeiro", demonstra fortemente a homofobia do discurso médico, onde tanto a transexualidade como a intersexualidade só podem ser compreendidas através de uma matriz heterossexual (ARÁN, 2006; BENTO, 2006; BUTLER, 2003). Isso nos permite pensar como a incorporação de novas tecnologias médicas 
reitera as normas de gênero através da normatização da masculinidade e da feminilidade e da exclusão da homossexualidade (ARÁN; CORRÊA, 2009).

Porém, para Hausman (1995), embora os estudos feministas tenham incorporado de forma produtiva a ideia de biopoder de Foucault para pensar as técnicas de si e a reiteração das normas de gênero, ${ }^{16}$ muitas vezes esta noção de tecnologia significa apenas uma metaforização da construção cultural dos corpos. Para ela, o que o fenômeno da transexualidade revela é a influência material da tecnologia médica, não apenas na construção da categoria de gênero, mas também no raciocínio que permite conceber um sistema de coerência e incoerência entre sexo e gênero. Os estudos sobre a materialidade das tecnologias de gênero (HARAWAY, 1991) como prática médica teriam assim uma autonomia relativa em relação aos estudos culturais também sobre as tecnologias de gênero (DE LAURETIS, 1989; BUTLER, 1993), sendo que estas duas noções podem ou não se sobredeterminar.

O problema aqui é que o material "tecnologias do gênero" nunca recebe nenhuma atenção: tecnologia é sempre metafórica, nunca compreendida como em seu sentido literal, denotativo. Assim, "gênero" como produto de tecnologias materiais (especialmente aquelas relacionadas ao corpo e suas funçôes), não apenas como um efeito de produção ideológica, desaparece como um possível objeto de investigação feminista. (HAUSMAN, 1995, p. 14).

Finalmente, como consequência desta proposição, a autora argumenta que o agenciamento transexual se fundamenta basicamente na demanda constante pela tecnologia médica. Destaca que transexuais precisam de serviços médicos para atingir seu objetivo, e o discurso sobre a transexualidade na medicina foi construído em parte pela justificativa proferida pelos próprios sujeitos transexuais para ter acesso às transformaçóes corporais. Neste sentido, para a autora, transexuais não teriam sido apenas vítimas de um sistema normativo de patologização do gênero, e sim, teriam influenciado diretamente na construção da categoria diagnóstica que culminou na codificação do transexualismo como transtorno de identidade de gênero em 1980. Assim, através da demanda de mudança de sexo, nos anos 1950 1960, transexuais teriam estrategicamente se distinguido de travestis e homossexuais e se engajado ativamente na produção de si como sujeitos (HAUSMAN, 1995). Esta dependência visceral da tecnologia médica e esta "subjetividade demandante" seria, em última instância, o que caracterizaria, do ponto de vista da autora, o fenômeno da transexualidade. 


\section{"Do sexo ao gênero"}

Joanne Meyerowitz (2002), quando escreve a história da transexualidade nos Estados Unidos, também destaca a importância da divulgação do caso de Christine Jorgensen para a constituição do fenômeno da transexualidade. Assim como Hausman (1995), a autora admite a importância das novas tecnologias médicas para o reconhecimento da possibilidade de mudança de sexo. Contudo, argumenta que isto só se tornou possível em função do debate já em curso sobre a mutabilidade do sexo, que nessa época já era um ponto alto na agenda europeia e americana, com a constante circulação de notícias, pesquisas, narrativas e "opiniōes" sobre os diversos significados da palavra "sexo". Deste material, destacam-se os estudos sobre os hormônios e cromossomos sexuais que complexificaram a noção de sexo biológico; o crescimento do trabalho feminino, inclusive braçal; a importância do movimento feminista na luta pela igualdade entre os sexos; e a emergência das culturas minoritárias gays e lésbicas. Todos esses fenômenos teriam iluminado a possibilidade de variação sexual na paisagem urbana e, segundo a autora, somente em função dessas transformaçoes podemos compreender como a narrativa de Christine Jorgensen pôde condensar e visibilizar o debate sobre a mutabilidade do sexo.

As histórias de Jorgensen e da transexualidade podem, assim, ser consideradas como o núcleo central de uma redescrição da noção de sexo no século XX. Neste contexto, a noção de sexo biológico se tornou mutável e plural, dividida em partes constituintes - cromossomos, hormônios e genitais - que podem ser modificadas; macho e fêmea não são mais considerados opostos e sim intercambiáveis; comportamentos ditos masculinos e femininos não surgem espontaneamente do sexo biológico; e o desejo sexual assume autonomia em relação ao sexo e ao gênero (MEYEROWITZ, 2002). No entanto, não se pode perder de vista que, muito antes disso, relatos de identificação cross-gender e o sentimento e o desejo de ser de outro sexo sempre teriam existido em outros momentos históricos e em outras culturas.

Desde o início do século XX, mais especificamente em torno de 1910, na Áustria, já se tinham notícias de experiências de tentativa de mudança de sexo dos animais. Além disso, nos anos 1920 também já eram divulgadas as cirurgias de mudança de sexo realizadas no Instituto de Ciência Sexual de Magnus Hirschfeld. Dentre elas, destaca-se particularmente a cirurgia realizada no artista dinamarquês Einar Wegener, que se tornou Lili Elbe (MEYOROWITZ, 2002). Esse período foi marcado pela formulação, por parte de Hirschfeld, da noção de intermediários 
sexuais a partir de seu estudo sobre travestilidade, segundo o qual hermafroditas, andrógenos, homossexuais e travestis constituíam tipos distintos, ou seja, variações possíveis da sexualidade. Outra importante teoria desenvolvida na época foi a da bissexualidade humana universal, proposta inicialmente por Wilhem Fliess e Sigmund Freud e incorporada por Weininger. Além disso, nos anos 1920-1930, uma nova revolução na compreensão da sexualidade se deu em função de descobertas no campo da endocrinologia. A partir da identificação química dos hormônios sexuais, ficou comprovado que homens e mulheres têm tanto hormônios masculinos como femininos e que estes últimos podem apresentar, em certas condiçôes, efeitos "masculinizantes" e vice-versa (SINDING, 2003; MEYOROWITZ, 2002). Estas teorias acabaram por desconstruir a noção de sexos distintos e opostos, oriunda do modelo do dimorfismo sexual, promovendo a ideia de um continuum entre os sexos que vai desde o hermafroditismo até as características tênues das sexualidades ditas normais. Tudo isto acompanhado de um movimento jurídico e político que contribuiu em muito para uma "liberação sexual" sem precedentes. Assim, para Meyerowitz:

Certamente, a tecnologia médica teve papel significativo na história da transexualidade. Mas a tecnologia sozinha não proveu o necessário nem foi uma pré-condição suficiente para a transexualidade moderna. As primeiras cirurgias transexuais tiveram lugar antes da invenção dos hormônios sintéticos e sem o benefício das sofisticadas técnicas de cirurgia plástica. [...]. A cirurgia de mudança de sexo, então, não teve raiz por causa da nova ou incomum tecnologia médica. Sua origem é em parte porque a Alemanha fez uma grande campanha pela emancipação sexual. Em Berlin, Hirschfeld e outros trabalham para remover os obstáculos legais e médicos para a variação de sexo e gênero, para capacitar homossexuais, crossdressers e aqueles que desejavam mudar seu sexo para viver sua vida como quisessem. Igualmente importante, a cirurgia de mudança de sexo na Europa confiou em uma nova definição do sexo (MEYEROWITZ, 2002, p. 21).

Esta nova concepção de sexo, acompanhada de histórias de transformação sexual por intervenção cirúrgica e utilização de hormônios, foi amplamente divulgada pelas revistas americanas populares e científicas nos anos 1930. Esta publicidade chamou a atenção de sujeitos transgêneros que começaram a utilizar a cultura e as informações disponíveis para redescrever e reconfigurar suas próprias identidades. Ainda que a demanda inicial por atendimento médico de transformação corporal não estivesse diretamente associada ao rótulo transexual, ela já problematizava os limites do sexo, exigindo novas elaborações. Esse é o panorama no qual, ao final 
dos anos 50, assistimos nos Estados Unidos a um deslocamento do sexo ao gênero. As teorias dos intermediários sexuais e da bissexualidade humana dão lugar a uma definição de "sexo psicológico" que vai determinar o conceito de "identidade de gênero". Alguns autores, como o próprio Benjamin, consideravam o sexo psicológico como um produto de interações entre genes e hormônios; outros, como Money, preconizavam que o gênero era produto de condicionamento e aprendizagem.

Desta maneira, muito antes do feminismo dos anos 60 - onde a noção de gênero será utilizada como um instrumento de análise crítica da dominação masculina -, Jonh Money, em 1947, já utiliza a palavra gênero para designar certa plasticidade da sexualidade, passível, na sua concepção, de ser moldada pela tecnologia. Esta noção será desenvolvida por Anke Ehrhardt e Joan e John Hampson no contexto do tratamento clínico e hormonal de bebês nascidos com genitália ambígua (MEYEROWITZ, 2002). Ao longo de suas pesquisas, Money buscou demonstrar a independência radical entre o social e o biológico. Deste modo, a educação seria modeladora do gênero dos indivíduos e este, por sua vez, prevaleceria em relação ao sexo (MONEY, 1969). No entanto, esta concepção deveras construtivista, se é que podemos nos expressar assim, seguia um modelo rígido de determinação da feminilidade e da masculinidade. ${ }^{17}$ De acordo com Löwy (2003), características "típicas" de um determinado gênero, tais como gostar de bonecas ou brincar de bola, eram dados de extremo valor, que, unidos à pressuposição de uma heterossexualidade natural, definiam como seria a adequação sexual, de modo a extinguir qualquer possibilidade de ambiguidade. Estas são as definições que irão fundamentar o fenômeno transexual.

Ainda segundo Meyerowitz (2002), mesmo considerando que no final dos anos 1970 e início dos anos 1980 - com a constituição da Associação Internacional Harry Benjamin de Disforia de Gênero e com sua inclusão no DSM - a transexualidade tenha sido efetivamente reconhecida no campo social, este fato não eliminou as tensões associadas à compreensão da variabilidade de gênero como transtorno mental. Inicialmente, o movimento feminista e os movimentos de gays e lésbicas e, mais recentemente, o movimento dos transgêneros, deram novos rumos para este debate, problematizando a rigidez dos protocolos médicos e a visão normativa do diagnóstico psiquiátrico.

Finalmente, para Meyorowitz (2002), tanto a transexualidade (termo utilizado atualmente) como transexualismo (termo utilizado nos anos 1950-1960), se 
referem a uma experiência na qual as pessoas desejam mudar suas características corporais de sexo. Tendo como referência a cultura norte-americana, transexuais são um subconjunto de indivíduos “transgêneros”. Porém, estas categorias não são estanques e sim intercambiáveis.

A mesma pessoa pode se identificar como uma lésbica bem masculina em um momento da vida e como um transexual FTM em outro. [...] O desejo de mudar o sexo no corpo não corresponde necessariamente a algum comportamento erótico padrão ou desejo sexual. Em termos de atração sexual, muitos transexuais se identificam como heterossexuais, isto é, transexuais masculinos para femininos frequentemente se veem como mulheres heterossexuais, e transexuais femininos para masculinos se veem como homens heterossexuais. Mas alguns transexuais se identificam como (e são reconhecidos como) homossexuais, bissexuais ou assexuados. [...] Pelas definições mais comuns atualmente, transexuais não são intersexos, um termo usado para descrever pessoas que são normalmente chamadas de "hermafroditas" e "pseudo-hermafroditas", pessoas com condiçôes físicas nas quais os genitais ou aparelho reprodutivo não se adequam exatamente à categoria de macho e fêmea. (MEYEROWITZ, 2002, p. 10).

Ainda na sua concepção, "transexuais frequentemente aparecem como algo maior que si mesmos", ou seja, ou como signo de alguma desordem mental, ou como símbolo de uma transgressão das normas de gênero. A autora afirma que busca evitar investir em transexuais um peso simbólico transistórico de um grupo que teria uma característica própria de relacionamento com a tecnologia, ou mesmo uma pretensão política de subversão da ideologia de gênero. Nesse sentido, uma ou um transexual, como qualquer outra pessoa, articulariam as possibilidades de construção de si conforme a linguagem e a cultura disponíveis.

\section{Considerações finais}

Se inicialmente a institucionalização da assistência a transexuais no Brasil esteve associada ao modelo estritamente biomédico, no qual o diagnóstico de transtorno de identidade de gênero tem como tratamento possível a cirurgia de transgenitalização, hoje a noção de saúde integral deve promover uma abertura para redescrições da experiência transexual. Este deslocamento exige, em parte, a problematização da gramática normativa dos sistemas de saber dos especialistas, que consideram o transexualismo uma patologia, dada a não-conformidade entre sexo biológico e gênero. Sabemos o quanto este diagnóstico veicula uma gramática 
normativa que acaba por considerar o transexualismo uma patologia ("transtorno de identidade") - pelo simples fato da não-conformidade entre sexo biológico e gênero, sem nenhum outro fundamento psicopatológico. Nesta gramática, gêneros inteligíveis são aqueles que mantêm uma continuidade entre sexo, gênero, práticas sexuais e desejo, por intermédio dos quais a identidade é reconhecida e adquire efeito de substância. Em tal caso, os espectros de descontinuidade e incoerência transformados em patologia só se tornam concebíveis em função deste sistema normativo (ARÁN, 2006).

O termo "transexualismo" e a noção de "transtorno de identidade" são oriundos de uma racionalidade que pressupóe que o sexo é algo definido pela natureza, fundamentado no corpo orgânico, biológico e genético, e que o gênero é algo que se adquire através da cultura. Esta compreensão se baseia na percepção de que o sexo homem ou mulher - é um dado natural, anistórico, e de que o gênero é uma construção histórica e social. Esta tese, porém, por um lado determinista e por outro, construtivista, restringe em muito a possibilidade de compreensão das subjetividades e das sexualidades. Sabemos que tanto o sexo como o gênero são passíveis de determinações históricas e políticas. Por outro lado, sabemos também o quanto a materialidade do corpo se impõe como um fato biológico e/ou intensivo que excede qualquer tentativa de uma apreensão normativa. Assim, as identificações de gênero são processos bastante complexos, inconscientes e corporais que nem sempre podemos acompanhar, apreender e descrever (ARÁN; PEIXOTO JUNIOR, 2007; LIONÇO, 2006). Essas identificações se fazem ao longo da vida, principalmente na primeira infância, a partir do encontro afetivo e corporal com o outro, o qual sempre está inscrito em determinada cultura que transmite valores e reitera ou não as normas de gênero. Desta forma, o processo de cuidado em saúde no caso da transexualidade deve suplantar qualquer perspectiva correcional e adaptativa.

Nas fronteiras da saúde, por influência do movimento feminista, do movimento de gays e lésbicas, e mais recentemente, do movimento de transexuais, travestis e transgêneros, alguns enunciados são deslocados dos discursos médicos e reapropriados em outros contextos, promovendo novos sujeitos do conhecimento, numa nova micropolítica de gênero. O que permanece como questão ética e política são os critérios para garantir o acesso às tecnologias de modificação do sexo corporal.

É importante reconhecer que a noção de transexualidade tem sido utilizada de diversas formas. O Coletivo Nacional de Transexuais vem propondo a noção de 
homens e mulheres que vivenciam a transexualidade com o objetivo de enfatizar que a transexualidade não é uma identidade, justamente porque as pessoas se definem e se reconhecem como homens e mulheres e não como transexuais. Outros grupos preferem utilizar a definição "Homens transexuais" e "Mulheres transexuais", incorporando em parte a noção de transexualidade como definição de si; e ainda um grupo minoritário prefere a noção de transgênero para expressar a possibilidade de um cruzamento de gêneros. Além disso, ainda que no meio médico exista uma clara distinção entre transexuais e travestis, várias pessoas transitam entre estas identidades. ${ }^{18}$ Finalmente, não há como não considerar que essas definições muitas vezes são moldadas a partir de uma exigência médica que prescreve a necessidade do diagnóstico de Transtorno de Identidade de Gênero como condição de acesso à saúde. Como afirma Lionço:

O que chama à atenção é o fato da descrição do transexualismo incluir, como critério diagnóstico, o desejo pela intervenção médica oferecida como solução para o dito transtorno, o que permite afirmar que o próprio saber médico é determinante na caracterização do tipo de quadro patológico, ou, dito em outros termos, a própria medicina estaria promovendo um certo ordenamento subjetivo. (LIONÇO, 2008, p. 3).

Neste sentido, trata-se de fazer valer os saberes locais, descontínuos, "desqualificados", "ilegítimos", contra e em negociação com as instâncias teóricas que pretendem filtrá-los, hierarquizá-los, ordená-los em nome de um conhecimento único, que se apresenta como "verdadeiro" e aplicável a qualquer um (FOUCAULT, 1977). Deslocamentos de saberes dominantes em direção a saberes locais e minoritários (HARAWAY, 1991) serão bem-vindos e devem ser incorporados na gestão de novas políticas.

\section{Referências}

ARÁN, M. A Transexualidade e a gramática normativa do sistema sexo-gênero. Ágora - Estudos em Teoria psicanalítica, Rio de Janeiro, v. 9, n. 1, p. 49-63, 2006.

ARÁN, M.; CORRÊA, M. Novas tecnologias em saúde e os sistemas normativos de sexo-gênero. In: GOMBERG, E.; MANDARINO, A.C. S. (Orgs.). Leituras das Novas Tecnologias em Saúde. Aracaju: Editora da Universidade Federal de Sergipe, 2009. p. 223-249. 
ARÁN, M. et al. Transexualidade e saúde: acúmulo consensual para propostas de saúde integral. Mimeo, 2008.

ARÁN, M.; LIONÇO, T. Mudança de sexo: uma questão de justiça para a saúde. Série Anis. Brasília, n. 53, p. 1-3, 2007.

ARÁN, M.; MURTA, D.; LIONÇO, T. Transexualidade e saúde pública no Brasil. Ciência e Saúde Coletiva [online], Rio de Janeiro, 2008. Disponível em: <http://www.abrasco.org.br/ cienciaesaudecoletiva/artigos/artigo_int.php?id_artigo=1419>. Acesso em: $30 \mathrm{dez} 2008$.

ARÁN, M.; ZAIDHAFT, S.; MURTA, D. Transexualidade: corpo, subjetividade e saúde coletiva. Psicologia e Sociedade, Porto Alegre, v. 20, nº 1, 2008.

ARÁN, M.; PEIXOTO JUNIOR, C. A. Subversōes do desejo: sobre gênero e subjetividade em Judith Butler. Cad. Pagu [online], Florianópolis, n. 28, p. 129-147, 2007. Disponível em: $<$ http://www.scielo.br/scielo.php?script=sci_arttext \&pid=S0104$83332007000100007 \& \operatorname{lng}=$ pt\&nrm=iso $>$. Acesso em: 30 jun 2007.

ATHAYDE, A. V. L. Transexualismo masculino. Arq Bras Endocrinol Metab, São Paulo, v.45, n. 4, p. 407-414, 2001.

AWAD, M. C. et al. The impact of male-to-female sex reassignment surgery on the quality of life of transsexual patients. In: CONGRESO DE LA SOCIEDAD LATINOAMERICANA DE MEDICINA SEXUAL, 9, 2007, Lima, Journal of Sexual Medicine, 2007a, v. 4, p. 24.

. Avaliação da qualidade de vida em pacientes transexuais: o impacto da transgenitalização. In: CONGRESSO BRASILEIRO DE UROLOGIA, 31, 2007, Salvador, International Brazilian Journal of Urology, 2007b, v. 33. p. 304.

SILVA, E. A. et al. Refinement of the genital surgery for the male-to-female transsexualism. In: CONGRESO DE LA SOCIEDAD LATINOAMERICANA PARA EL ESTÚDIO DE LA IMPOTENCIA Y LA SEXUALIDAD, 8, 2006, Punta del Este, Journal of Sexual Medicine, 2005, v. Jan. p. 36. (Trabalho premiado em primeiro lugar, categoria Video).

BRASIL. Ministério da Saúde. Portaria n. 1.707/GM, de 18 de agosto de 2008. Institui, no âmbito do SUS, o Processo Transexualizador, a ser implantado nas unidades federadas, respeitadas as competências das três esferas de gestão. Diário Oficial da União, Brasília, DF, 19 de agosto de 2008 (a).

. Ministério da Saúde. Portaria n. 2.227/GM, de 14 de outubro de 2004. Dispóe sobre a criação do Comitê Técnico Saúde para a formulação de proposta da Política Nacional de saúde da população gays, lésbicas, transgêneros e bissexuais - GLTB. Diário Oficial da União, Brasília, DF, 14 de outubro de 2004 .

BENJAMIN, Harry. The transsexual phenomenon. New York: Julian Press, 1966. Disponível em: < http://www.symposion.com/ijt/benjamin/index.htm >. Acesso em: 20 ago. 2006. 
BENTO, Berenice. A reinvenção do corpo. Sexualidade e gênero na experiência transexual. Rio de Janeiro: Garamond, 2006.

BUTLER, Judith. Gender Regulations. In: . Undoing Gender. Nova York: Routledge, 2004, p. $40-55$.

. Problemas de gênero. Feminismo e subversão da identidade. Rio de Janeiro: Civilização Brasileira, 2003.

. Bodies that Matter. On the discursive limits of “sex”. New York: Routledge, 1993.

CASTEL, P. H. Algumas reflexões para estabelecer a cronologia de "fenômeno transexual" (19101995). Revista Brasileira de História, São Paulo, v. 21, n. 41, p. 77-111, 2001.

CAULDWELL, D. O. Psychopathia Transexualis. International Journal of Trangenderism. Minessota, v. 5, n. 2 abr./jun 2001. Disponível em: < http://www.symposion.com/ijt/cauldwell/cauldwell 02.htm>. Acesso em: 10 out. 2006.

CONSELHO FEDERAL DE MEDICINA. Resolução no. 1.652, de maio de 2002. Dispõe sobre a cirurgia de transgenitalização e revoga a Resolução CFM 1.482/97. Diário Oficial da Uniāo, 2002, 2 dez. Disponível em: < http://www.portalmedico.org.br/resolucoes/cfm/2002/ 1652_2002.htm > Acesso em: 12 abr. 2005.

CORREAA, M. Sexo, sexualidade e diferença sexual no discurso médico: algumas reflexões. In: LOYOLA, M. A. (Org.). A Sexualidade nas Ciências Humanas. Rio de Janeiro: EdUERJ, 1998. p. 69-92.

COSTA, A. M.; LIONÇO, T. Democracia e gestão participativa: uma estratégia para a equidade na saúde? Saúde e Sociedade, São Paulo, v. 15, n. 2, p. 47-55, 2006.

COSTA, E. M. F. A Complexidade da terapia hormonal. Relatório da Jornada Nacional sobre Transexualidade e Assistência Pública no Brasil, 2006.

DE LAURETIS, T. Technologies of Gender. Bloomington: Indiana University Press, 1989.

DELEUZE, G. Post-scriptum sobre as sociedades de controle. In: . Conversaçôes 1972 1990. Rio de Janeiro: Editora 34, 1992.

DSM-IV-TR Manual Diagnóstico e Estatístico de Transtornos Mentais. Trad. Cláudia Dornelles. 4 ed. Porto Alegre: Artmed, 2002.

FOUCAULT, M. Sujeito e poder. In: DREYFUS, H.; RABINOW, P. Michel Foucault: uma trajetória filosófica. Para além do estruturalismo e da hermenêutica. Rio de Janeiro: Forense Universitária, 1995. p 231-249.

. História da Sexualidade I. A vontade de saber. Rio de Janeiro: Graal, 1988.

. Cours du 7 janvier, 1976. Dits et écrits II. Paris: Galimard, 1977. p. 160-174. 
JORNADA NACIONAL SOBRE TRANSEXUALIDADE E ASSISTÊNCIA PÚBLICA NO

BRASIL, 1., 2005, Rio de Janeiro - Relatório Final. Disponível em: < http://www.ims.uerj.br/ transexualidadesaude/ >. Acesso em: 05 jan. 2006.

HARAWAY, D. Simians, Cyborgs, and Women. The Reinvention of Nature. London: Free Association Books, 1991.

HAUSMAN, B. Changing Sex: Transsexualism, thechnology and the Idea of Gender. Durham: Duke University Press, 1995.

LIONÇO, T. Bioética e sexualidade: o desafio para a superação de práticas correcionais na atenção à saúde de travestis e transexuais. Série Anis. Brasília, n. 54, p. 1-6, 2008.

. Um olhar sobre a transexualidade a partir da perspectiva da tensionalidade somato-psíquica. Tese (Doutorado em Psicologia) - Instituto de Psicologia, Universidade de Brasília, Brasília, 2006.

LOBATO, M. I. et al. Transexualismo: Uma revisão. Jornal Brasileiro de Psiquiatra. Rio de Janeiro, v. 50, n. 11-12, p. 379-388, 2001.

LOBATO. M. I. et al. Follow-Up of Sex Reassignment Surgery in Transsexuals: A Brazilian Cohort. Arch Sex Behav, v. 35, p. 711-715, 2006.

LÖWY, I.; ROUCH, H. La distinction entre sexe e genre: une historie entre biologie et culture. Paris: Harmattan, 2003.

LOYOLA, M. A. Sexualidade e medicina: a revolução do século XX. Cad. Saúde Pública. Rio de Janeiro, v. 19, n. 4, 2003.

MARTINS, A. Biopolítica: o poder médico e a autonomia do paciente em uma nova concepção de saúde. Revista Interface: Comunicação, saúde, educação. v. 8, n. 14, 2004.

MATTOS, R. A Integralidade na prática (ou sobre a prática da integralidade). Cad. Saúde Pública. Rio de Janeiro, v. 20, n. 5, p. 1.411-1.416, 2004.

MEYEROWITZ, J. How sex changed. A history of transsexuality in the United States. Cambridge: Harvard University Press, 2002.

MONEY, J. Sex reassignment as related to hermaprhoditism and transsexualism. In: GREEN, R.; MONEY, J. Transsexualism and sex reassignment. Baltimore: The Johns Hopkins Press, 1969. p. $91-114$.

MURTA, D. A psiquiatrização da transexualidade: análise dos efeitos do diagnóstico de Transtorno de Identidade de Gênero sobre as práticas de saúde. Dissertação (Mestrado em Saúde Coletiva) - Instituto de Medicina Social, Universidade do Estado do Rio de Janeiro, Rio de Janeiro, 2007.

PELÚCIO, L. Toda quebrada na plástica - corporalidade e construção de gênero entre travestis paulistas. Campos: Revista de Antropologia Social, v. 6, n. 1 e 2, 2005. Disponível em: <http:// calvados.c3sl.ufpr.br/ojs2/index.php/campos/issue/view/424>. Acesso em: dez. 2009. 
PRECIADO, B. Elmanifesto contrasexual. Madrid: Opera Prima, 2002.

SAADEH, A. Transtorno de identidade sexual: um estudo psicopatológico de transexualismo masculino e feminino. 2004. Tese (Doutorado em Ciências) - Departamento de Psiquiatria da Faculdade de Medicina, Universidade de São Paulo, São Paulo, 2004.

SINDING, C. Le sexe des hormones: l'ambivalence fondatrice des hormones sexuelles. In: LÖWY, I.; ROUCH, H. (Orgs). La distinction entre sexe et genre. Cahiers du Genre. Paris: L'Harmattan, 2003. p. 39-56.

STOLLER, R. J. A experiência transexual. Rio de Janeiro: Imago, 1982.

. The male transsexual as "experiment". International Journal of Psychoanalysis. Los Angeles, v. 54, p. 215-225, 1973.

VENTURA, M. Transexualismo e respeito à autonomia: um estudo bioético dos aspectos jurídicos e de saúde da "terapia para mudança de sexo". 2007. Dissertação (Mestrado em Saúde Pública) Escola Nacional de Saúde Pública, Fundação Oswaldo Cruz, Rio de Janeiro, 2007.

ZAMBRANO, E. Trocando os documentos: um estudo antropológico sobre a cirurgia de troca de sexo. 2003. Dissertação (Mestrado em Antropologia Social) - Instituto de Filosofia e Ciências Humanas, Universidade Federal do Rio Grande do Sul, Porto Alegre, 2003.

\section{Notas}

${ }^{1}$ Levantamento realizado a partir do relatório da I Jornada sobre Transexualidade e Saúde no Brasil (UERJ, 2005); dos contatos realizados nas reuniōes do Comitê Saúde LGBTT do Ministério da Saúde sobre o Processo Transexualizador no SUS (BRASIL, 2006); da participação no Seminário Nacional: Saúde da população LGBTT na construção do SUS (2007), na Oficina sobre o Processo Transexualizador no SUS (2007), nos Fóruns do Coletivo Nacional de Transexuais e informações disponibilizadas por profissionais de diversos serviços e acesso à página http://www.ims.uerj.br/ transexualidadesaude. Destes serviços, apenas sete se dispuseram a responder a um questionário detalhado. Um dos serviços contatados foi excluído dessa etapa da pesquisa exploratória por se tratar de um programa assistencial particular.

${ }^{2}$ Os serviços pesquisados foram os seguintes: 1) Programa de Transtorno de Identidade de Gênero (PROTIG) do Hospital de Clínicas de Porto Alegre/UFRGS; 2) Unidade de Urologia Reconstrutora Genital do Hospital Universitário Pedro Ernesto/UERJ; 3) Ambulatório de Transexualidade - Projeto Sexualidade (PROSEX) do Instituto de Psiquiatria do Hospital das Clínicas da Faculdade de Medicina/ USP; 4) Projeto Transexualismo do Hospital das Clínicas de Goiânia; 5) Programa de Atendimento a Transexuais e Cirurgia de Transgenitalização do Hospital Universitário Clementino Fraga Filho UFRJ; 6) Ambulatório de Endocrinologia Especial (Transtorno de Identidade de Gênero) do Instituto Estadual de Diabetes e Endocrinologia Luiz Capriglione (IEDE). Além destes, foram inicialmente 
contatados e posteriormente excluídos da análise pelos motivos referidos acima: 7) Hospital das Clínicas da UFMG; 8) Transexualidade - Serviço de Urologia da Faculdade de Medicina de São José do Rio Preto da Faculdade de Medicina e Hospital de Base; 9) Atendimento Ambulatorial a Transexuais do Hospital Universitário de Brasília; 10) Departamento de Psicologia do Instituto Paulista de Sexualidade.

${ }^{3}$ Para mais detalhes, ver Athayde (2001) e Costa (2009).

${ }^{4}$ Resolução no ${ }^{\circ}$ 1.652, de maio de 2002, do Conselho Federal de Medicina.

${ }^{5}$ Para mais detalhes, ver Awad et al. (2007a e 2007b); Silva et al. (2006 e 2005) e Lobato et al. (2006).

${ }^{6}$ Para mais detalhes, ver Arán, Zaidhaft e Murta (2008); Sadeeh (2004) e Lobato et al. (2001).

${ }^{7}$ Ver Arán, Murta \& Zaidhaft. Transexualidade e cirurgia de transgenitalização: um desafio para medicina. Protocolo 073/02 CEP/HUCFF/UFRJ.

${ }^{8}$ Para mais detalhes, ver Relatório Final da Jornada Nacional sobre Transexualidade e Assistência Pública no Brasil (2005).

9 Ver documento "Transexualidade e saúde: acúmulo consensual para propostas de saúde integral" (ARÁN et al., 2008).

${ }^{10}$ Programa de Transtorno de Identidade de Gênero (PROTIG) do Hospital de Clínicas de Porto Alegre/UFRGS; Unidade de Urologia Reconstrutora Genital do Hospital Universitário Pedro Ernesto/ UERJ; Ambulatório de Transexualidade - Projeto Sexualidade (PROSEX) do Instituto de Psiquiatria do Hospital das Clínicas da Faculdade de Medicina/USP e Projeto Transexualismo do Hospital das Clínicas de Goiânia.

${ }^{11}$ Vários autores, como Ventura (2007) e Zambrano (2003), argumentam que a possibilidade de mudança da identidade civil resolveria em grande parte os problemas cotidianos de transexuais, tais como as questôes relacionadas ao trabalho, estudo, planos de saúde etc.

12 Para um debate sobre os mecanismos de poder e de normatização que atravessam a assistência à saúde de pessoas travestis e transexuais, ver Lionço (2008).

${ }^{13}$ Para uma análise mais profunda sobre normas de gênero, ver Arán e Peixoto Junior (2007).

${ }^{14}$ Alguns autores têm analisado a intensa contribuição da medicina durante o século XX, principalmente nos campos da sexologia, da reprodução assistida e da epidemiologia, para a consolidação de um modelo de controle social que se faz através de uma produção discursiva sobre o sexo. Para uma discussão mais aprofundada, ver Foucault (1988), Loyola (2003) e Corrêa (2006).

${ }^{15}$ Em relação ao diagnóstico de "Transtorno de Identidade de Gênero", o Manual Diagnóstico Estatístico de Doenças Mentais (DSM-IV) considera que: "Deve haver evidências de uma forte e persistente identificação com o gênero oposto, que consiste do desejo de ser, ou a insistência do indivíduo de que ele é do sexo oposto (Critério A). Esta identificação com o gênero oposto não deve refletir um mero desejo de quaisquer vantagens culturais percebidas por ser do outro sexo. Também deve haver evidências de um desconforto persistente com o próprio sexo atribuído ou uma sensação de inadequação no papel 
de gênero deste sexo (Critério $B$ ). O diagnóstico não é feito se o indivíduo tem uma condição intersexual física concomitante (por ex., síndrome de insensibilidade aos andrógenos ou hiperplasia adrenal congênita) (Critério C). Para que este diagnóstico seja feito, deve haver evidências de sofrimento clinicamente significativo ou prejuízo no funcionamento social ou ocupacional ou em outras áreas importantes da vida do indivíduo (Critério D)”.

${ }^{16}$ Inspirada na teoria de Foucault, Butler (2004) considera que o poder não tem um caráter puramente opressor, afirmando que as regulaçóes de gênero seriam uma modalidade de regulação específica que constitui a subjetividade. Em sua concepção, o gênero por si mesmo é uma norma que, quando reiterada, impõe efeitos substancializantes e produz sujeitos inteligíveis.

${ }^{17}$ É importante destacar que esta concepção superficial de separação entre o sexo (biológico) e gênero (construção cultural) teve consequências nefastas no tratamento de certos indivíduos (ver, por exemplo, o caso de David Reimer comentado por Butler, 2004). No entanto, desde os anos 1960-1970, com o fortalecimento do movimento feminista, este conceito tem adquirido outros significados muito mais complexos e produtivos.

${ }^{18}$ Sobre algumas especificidades da experiência da travestilidade, ver Pelúcio (2005). 
Abstract

From the Gender Identity Disorder diagnosis to the redescription of the transsexuality experience: a reflection on gender, technology and health

Based on a study on health practices of the main services that assist transsexuals in Brazil, this paper discusses the challenges for public policies management for this population, particularly, the need for a Gender Identity Disorder diagnosis as condition to access. To light up this debate, there is a reflection on gender, technology and health, based on the contributions of Bernice Hausman and Joanne Meyerowitz on the constitution of the transsexuality phenomenon in mid $20^{\text {th }}$ century. It highlights the importance of analyzing the progress of medical technology and the revolution of custom's influence on the debate on the immutability of the sex and on the construction of the gender category as condition to understand the reason why the regulation of health access for the modification of bodily sexual characteristics was associated with the definition of the transsexual condition. Then it argues that if firstly the institutionalization of assistance to transsexuals in Brazil was associated with the strictly biomedical model, the notion of integral health must promote an opening for the redescriptions of transsexual experience in a permanent articulation between the dominant biopolitical knowledge and the multiple local and minority's types of knowledge.

> Key words: transsexuality; health; gender; technology; subjectivity; culture. 